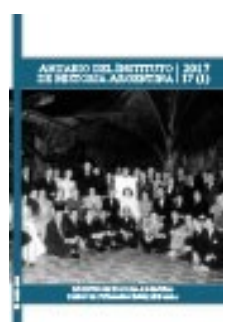

Anuario del Instituto de Historia Argentina, vol. 17, nº 1, e033, junio 2017.

ISSN 2314-257X

Universidad Nacional de La Plata.

Facultad de Humanidades y Ciencias de la Educación.

Centro de Historia Argentina y Americana

\title{
Ócio e lazer na regulamentação das férias operárias: a OIT e o caso brasileiro na primeira metade do século XX
}

\author{
Leisure and recreation on the holidays regulation: the ILO and \\ Brazil in the first half of XXth century
}

\section{Guilherme Machado Nunes *}

* Mestre e Doutorando em História pela Universidade Federal do Rio Grande do Sul (UFRGS), Brasil | guilherme.mnunes@gmail.com

\section{PALAVRAS-CHAVE RESUMO}

Lei de Férias $\quad$ O presente trabalho investiga a legislação acerca das férias em alguns dos países-membros da OIT, e mais especificamente no Brasil. Se buscará compreender como alguns desses países ocidentais trataram do tema e como ele surgiu no Brasil em meados dos anos 1920. Em um primeiro momento se descreverá a conjuntura na qual surge a OIT e suas resoluções, passando pela aprovação de leis de férias em diversos locais. Em seguida, se estudará a lei no Brasil: primeiro com a apresentação da

Greves trajetória da lei no período de sua aprovação até sua primeira reelaboração (1925-1934), e finalmente a luta dos operários para garanti-las.

\section{KEYWORDS}

Holiday Act

Labour legislation

Strikes

Leisure

\section{ABSTRACT}

This paper investigates the legislation on holidays in some of the member countries of the ILO, and more specifically in Brazil. It will seek to understand how these western countries treated the issue as he emerged in Brazil in the mid-1920s. At first it will be described the situation in which the ILO and its resolutions arise, passing through the adoption of vacation laws in various locations. Then, the law will be studied in Brazil: first with the presentation of the path of the law from the period of approval to its first reprocessing (1925-1934), and finally the struggle of the workers to ensure it. 


\section{Introdução}

Os momentos posteriores à Primeira Guerra Mundial foram una época de grandes debates a propósito das condições de vida da classe trabalhadora em todo o mundo. A Organização Internacional do Trabalho (OIT), instituição derivada do Tratado de Versalles, de 1919, constituiu um espaço de discussão sobre este tema cada vez mais importante. Os membros da entidade se encontravam uma vez por ano e discutiam temas específicos a cada encontro, tais como a jornada laboral, o trabalho de mulheres e crianças, e acidentes de trabalho. Neste momento, a Revolução Russa de 1917 se apresentava como um horizonte possível para a classe trabalhadora, e a discussão de melhores condições de vida e trabalho foi uma tentativa dos governos dos países ocidentais de oferecer uma resposta dentro do capitalismo à alternativa bolchevique tratando de evitar situações de miséria laboral similares às encontradas na Rússia czarista. No Brasil, também por conta de una onda de greves e mobilizações operárias entre os anos de 1917 e 1919, este é o período em que surgem a Lei de Acidentes de Trabalho (1919), uma polêmica Lei de Férias (1925) e o Código de Menores (1927). Além das leis, foi criado o Conselho Nacional do Trabalho (1923), responsável por regulamentar e fiscalizar estas e outras leis.

A Lei de Férias foi uma das medidas que mais gerou conflitos entre o operariado e a burguesia industrial brasileira. Enquanto esta tentara de todas as formas dissuadir o Estado da ideia de regulamentar o descanso remunerado de seus funcionários, aquele denunciara diversas vezes o descumprimento da legislação por seus patrões.

Este trabalho pretende apresentar como as férias foram regulamentadas em alguns países da OIT, de maneira comparada com o caso de Brasil, que apresentou algumas particularidades. O que se busca é justamente compreender essas especificidades, assim como o contexto global no qual esta lei foi aprovada, compará-la com as férias remuneradas de outras localidades e especular sobre algumas das razões que poderia haver levado o governo do Brasil a promulgar a lei, que é um dos primeiros benefícios gerais regulados pelo Estado.

Na primeira parte será exposto como a ideia de um descanso remunerado foi ganhando força a princípios do século XX em países do ocidente, até que se tornaram lei em diversos lugares. Em seguida serão discutidas questões específicas da realidade brasileira e, por último, se discutirá mais detalhadamente a lucha da classe trabalhadora pelas férias remuneradas.

\section{Origens e consolidação das férias operárias}

Os primeiros congressos destinados a discutir normas para o trabalho ocorreram no século XIX. Se especula que o primeiro tenha ocorrido em Genebra, em 1866, seguido por Baltimore, em 1877, e pela Conferência de Berlim, em 1890, até chegar ao mencionado Tratado de Versalles, em 1919. Em Berlim se discutiram pela primeira vez, de maneira geral, questões como o trabalho infantil e de mulheres, o descanso dominical e a jornada de trabalho (Martins, 2000, p. 25).

No mundo do trabalho, Paul Lafargue reivindicou o "direito à preguiça” no final do século XIX. A II Internacional, por sua vez, quando defendeu a divisão do dia em 8 horas de sono, 8 de trabalho e 8 de descanso, de alguma maneira também afirmou a garantia de um período destinado ao ócio. O Primeiro Congresso Socialista Operário Internacional, que teve lugar em Paris em 1889, por exemplo, enfatizou a necessidade de 36 horas de repouso ininterruptas por semana para o proletariado, com o propósito de "lutar contra a organização social que o esmaga” (Carone, 1993, p. 35).

As primeiras medidas referentes a férias que foram registradas nos remetem a 1905 quando diversos segmentos operários da Alemanha, Áustria-Hungria, Noruega e Dinamarca já desfrutavam do beneficio. Entre 1919 e 1925, países como Finlândia, Itália, Tchecoslováquia e Polônia concederam férias a 
trabalhadores das fábricas, mineiros, jornalistas e inclusive empregadas. Segundo a historiadora argentina Elisa Pastoriza (2008),

Después de la Primera Guerra Mundial las vacaciones pagas recibieron un fuerte impulso por la adopción, en gran cantidad de países, de una legislación que las hacía obligatorias. [...] El decenio que precede a la Segunda Guerra Mundial, caracterizado por la crisis, la expansión del desempleo y de los antagonismos nacionales, es el de un inmenso esfuerzo por organizar el tiempo de ocio de los trabajadores. Así, las vacaciones pagas fueron instauradas en la mayoría de los países occidentales en los años treinta. Su generalización implicó tres actores sociales: los empleadores y sus organizaciones, los sindicatos, y los poderes públicos. El peso relativo de cada uno de estos grupos fue variando de acuerdo con los países y las épocas.

Desta forma, entre 1926 e 1934, Luxemburgo, Grécia, Romênia, Chile, México, Espanha, Suécia, Per e Portugal -além do próprio Brasil- também legislaram sobre o tema. Em 1936, França, Iraque, Bélgica e Bulgária regulamentaram as férias. De maneira geral se garantiu a lei depois de seis meses de trabalho, e para operários fabris, depois de um ano (Horden, 1990, p. 20). Quando a lei foi aprovada no Brasil em 1925, como veremos adiante, os empresários nacionais diziam que as férias seriam exóticas à realidade de um país de industrialização tardia como o Brasil. Porém, quando olhamos o contexto mais geral, os países de industrialização tardia compõem justamente a maioria a conceder este beneficio.

A OIT, em 1919, já recomendava que se reservasse algum tempo de "repouso absoluto" aos trabalhadores, o que seria "fundamental para manter sua sanidade psíquica e moral" (Harden, 1990, p. 25). A questão se apresentava como aparentemente fácil de legislar, e talvez isto ajude a explicar a grande adesão de países majoritariamente periféricos a tal direito entre 1919 e 1936. O Uruguai, por sua vez, um dos países mais avançados em termos de direitos laborais $\underline{\underline{1}}$, entre 1914 e 1923 aprovou leis acerca dos acidentes de trabalho, jornada de oito horas, proibição de trabalho noturno, pensões e aposentadoria, descanso semanal obrigatório de um dia por semana, salário mínimo (inclusive para trabalhadores rurais) e uma curiosa lei que previa “cadeiras para que as operárias e empregadas descansarem quando suas tarefas assim permitissem” (Porrini, 2002, p. 101). É possível que isto confirme a hipótese das férias como uma alternativa a outras questões mais importantes para o movimento operário: em um país em que as principais bandeiras dos trabalhadores e trabalhadoras de período já estavam regulamentadas, as férias somente surgiriam algum tempo depois, já em princípios dos anos 1930.

O caso da Argentina também é curioso: percebendo o apelo que a medida tinha entre a classe trabalhadora, Juan Domingos Perón utilizou as férias em um projeto político, o turismo obrero. Desde os anos 1940,

el turismo tuvo una fuerte raigambre en el peronismo, en la esperanza que debía impactar a los argentinos para que amaran su tierra natal, a la que conocían demasiado poco. Con este discurso desde los poderes públicos y las dirigencias sindicales se alentaba a los trabajadores a enriquecer su cultura y conocer a otros trabajadores a través de las vacaciones.

Así, bajo la tutela de la nueva consigna peronista, el turismo obrero o social, se ensayaron los planes vacacionales y excursiones populares. El ocio popular comprendió dos coordenadas claramente visualizadas: las áreas marginales que se hallaban en la órbita de Parques Nacionales y aquellos ya elegidos por las elites y las clases medias. (Pastoriza, 2008).

O ócio e a recreação dos operários surgiam como questões importantes e estiveram em disputa, o que foi prontamente percebido pelo movimento operário organizado. Segundo Franciso Foot Hardman, a socialdemocracia de la II Internacional entendia o ócio dos trabalhadores como uma forma de liberdade e ritual coletivo, e tanto eles como os militantes anarquistas pensavam nas festas e outras atividades como grandes 
oportunidades de propaganda considerando que estes momentos "tinham potencial 'doutrinário, educador e ideológico'.” (Foot-Hardman, 1981, p. 45). Cresceu dessa forma a importância dos eventos coletivos fora das fábricas, como picnics e outras festividades operárias.

No Uruguay, por exemplo, Rodolfo Porrini destaca o papel que estes meetings tiveram e de que maneira as organizações comunistas e anarquistas trataram de "aproveitar-se" dessas oportunidades para recrutar novos membros para suas organizações:

¿Qué hace la gente cuando no trabaja? Luego de la jornada de trabajo las personas tenían "tiempo libre” para muchas cosas, y las izquierdas de las primeras décadas del siglo XX lo pretendían encauzar hacia la militancia y sus múltiples actividades culturales y de sociabilidad. Así, convocaban a los trabajadores montevideanos a los locales partidarios, ateneos y a las veladas culturales en salas de cines y teatros. Y allí iban unos centenares de asalariados y sus familias. Otra de las opciones que las izquierdas y sindicatos desarrollaron como propuestas alternativas fueron las actividades al "aire libre”, tanto en los pic-nics como en la práctica de deportes. (Porrini, 2011, p. 109).

Há ao menos una situação conhecida na cidade de Porto Alegre em que um destes meetings -que incluía um torneio de futebol- foi fundamental para o recrutamento de um militante, o caso do metalúrgico Eloy Martins, em 1928:

Eloy jogava também no time de futebol da [fábrica] Alcaraz e, ao disputar um torneio, foi apresentado por Ramão [colega de trabalho filiado ao Partido Comunista do Brasil] a "um moço, que de uma explanação política, gentilmente nos ofereceu exemplares de 'A Classe Operária”' [jornal do Partido Comunista]. Uma semana depois, o jovem metalúrgico já havia ingressado no Bloco Operário e Camponês [BOC, sigla eleitoral do partido]. (Fortes, 2004, p. 278).

Assim, estas situações foram boas ocasiões para estreitar relações políticas e afetivas, e nos parece que a luta por férias ou outros períodos de descanso eram, em alguma medida, uma tentativa de garantir a expansão destes tipos de eventos. Segundo Porrini, "los picnics, paseos campestres y excursiones de las izquierdas buscaban tanto disfrutar de la naturaleza y reforzar la camaradería, como fomentar la expectativa y el sueño en una sociedad igualitaria o socialista” (Porrini, 2011, p. 111).

Inclusive havia lugares onde surgiam colônias e outras localidades especializadas em receber à classe trabalhadora durante suas férias. Eric Hobsbawm menciona a criação de uma espécie de "balneário operário", onde se passavam as "típicas férias das classes trabalhadoras" a fins do século XIX, em Blackpool, na Inglaterra. Não fica claro, no entanto, se essas férias foram regulamentadas e generalizadas (Hobsbawm, 2000, p. 268). Sobre esta questão, Pastoriza (2008), menciona que

en el decenio de 1870, los trabajadores de las ciudades industriales del condado de Lancashire, una de las primeras sociedades de consumo de la clase obrera del mundo, empezaron a pasar hasta cinco días estivales junto al mar, extendidos a una semana -sin embargo, no pagas- participando, diez años después, en la generación de la ciudad balnearia Blackpool.

Deste modo, na Inglaterra, apesar da falta de remuneração referente ao período de descanso, ao final do século XIX já se tinha uma espécie de mercado econômico a propósito das férias, com complexos, praias, comércio e um consumo orientado aos trabalhadores em seus momentos fora das fábricas.

O caso da França foi um pouco distinto: o tema das férias parece haver sido especialmente sensível aos franceses, e desde 1853 os funcionários públicos deste país já tinham este direito. Em 1900, foi a vez dos ferroviários; em 1905, dos trabalhadores da companhia de eletricidade; e, em 1907, o sindicato dos mineiros obteve o beneficio para toda a categoria (Cf. Richez; Strauss, 1990, p.7). Em 1925, o Ministério do Trabalho 
francês fez una pesquisa nas indústrias do país acerca do tema. Alguns setores tinham acordos diretos com os patrões, mas frequentemente as férias não eram remuneradas e suas condições mudavam muito segundo o ofício e a região. A principal conclusão foi que o direito se concentrava em Paris enfrentando muita resistência das empresas de automóveis como Renault e Citroën (Richez; Strauss, 1990, p. 21). Segundo Richez e Strauss foi a partir deste momento que se tornaram frequentes as greves reivindicando férias. De acordo com estes autores, a recreação entrou na ordem do dia da classe trabalhadora no período entre guerras e, com o aumento do número de associações musicais, esportivas e recreativas, haveria um aumento correspondente do desejo de um tempo maior de descanso.

Stéphane Sirot, por seu turno, dirige sua atenção ao fato de que, pelo menos desde 1919, Paris registrou manifestações demandando férias remuneradas. Entre este ano e a aprovação das congés payés pelo governo da Frente Popular, em 1936, a capital francesa experimentou 79 greves reivindicando tal direito (Sirot, 1996, p. 96). É verdade que, segundo o autor, este número representa apenas 3\% das 2453 greves ocorridas no período, mas não se pode depreciar essa quantidade. Além disso, não é possível quantificar qual foi a intensidade dessas 79 greves, mas talvez elas ajudem a explicar porque em 1936 a França era o único país de industrialização avançada que tinha férias generalizadas para toda a classe trabalhadora.

A classe patronal francesa não foi muito receptiva em relação a este beneficio, especialmente as fabricantes de automóveis do interior do país, como se referiu antes. A seguir, vamos investigar como se articularam as principais justificativas utilizadas pelos patrões brasileiros para rechaçar a intervenção estatal no mundo privado das relações laborais, e como este pensamento foi mudando nas distintas conjunturas. Por fim, se verá qual foi a reação da classe trabalhadora a cada um destes processos.

\section{A trajetória da lei no Brasil}

Em Brasil, em dezembro de 1925 foi aprovada a Lei 4.982, que garantia a todos os trabalhadores urbanos o direito a quinze dias de férias remuneradas anuais. Segundo Alexandre Fortes (2007, p. 1),

Este pode ser considerado, na verdade, o primeiro benefício trabalhista geral estabelecido no Brasil e, juntamente com o Código de Menores e a Lei de Acidentes de Trabalho, deu início a uma nova fase na regulamentação das relações de trabalho no país, já prenunciada pela criação do Conselho Nacional do Trabalho (CNT) em 1923.

A lei, no entanto, somente foi publicada no Diário Oficial em outubro de 1926. Originalmente se previa o benefício apenas aos trabalhadores do comércio, mas a sua aprovação passou a incluir os trabalhadores da indústria, o que foi fortemente desaprovado pelos industriais brasileiros. Como destaca Lima (2005, pp. 9899),

As associações patronais ligadas à indústria brasileira [como o Centro Industrial do Brasil e os Centros das Indústrias de Fiação e Tecelagem do Algodão do Rio de Janeiro e de São Paulo] foram unânimes em reprovar a inclusão da classe operária entre os trabalhadores beneficiados pela lei de férias, afirmando tratar-se de grande imprudência de legisladores "teóricos e sonhadores impenitentes”, desconhecedores do cotidiano da indústria brasileira.

Como exposto anteriormente, não é acidental que estas leis comecem a surgir e a serem debatidas em um período em que a classe trabalhadora se encontrava organizada, mobilizada e protagonizando grandes greves por todo o país. Dessa forma, ao mesmo tempo em que percebemos a emergência de uma "nova mentalidade de proteção aos fatores de produção", também é possível interpretar esse conjunto de leis como um mecanismo para incorporação e desmobilização da classe trabalhadora, como observou Angela de Castro Gomes (1979, pp. 34-35). Esta tentativa fica um pouco mais clara quando percebemos que, em um primeiro 
momento, a referida lei não constava nas pautas clássicas de reivindicações dos trabalhadores de Brasil $\stackrel{2}{\text {. }}$ Sobre isto, Fortes afirma:

Quando a lei foi finalmente aprovada pelo Congresso em 1925, o tema já estava em debate havia mais de oito anos. É difícil determinar as causas que levaram ao estabelecimento deste direito trabalhista. Mas o fato de não integrar as lutas do movimento operário pode haver influenciado sua aprovação (2007, p. 2).

Este raciocínio certamente ajuda a compreender a demora na regulamentação da jornada laboral e do saláriomínimo, principais bandeiras do operariado ao largo de a Primeira República Brasileira (1889-1930). Não obstante, a ausência da palavra férias não significava que não houvesse uma demanda por maior tempo livre e uma emergência de atividades de lazer proletário: como exposto anteriormente, este também vinha ocorrendo em outras partes do mundo. Diminuir a jornada laboral, como diziam os próprios militantes, "facilita[ria] o descanso, o estudo, a educação associativa, a emancipação intelectual e o combate ao alcoolismo" (Pinheiro, Hall, 1979, p. 50), por exemplo. Assim, quando o deputado do Rio de Janeiro Henrique Dodsworth propôs a lei, se por um lado não era sistematicamente defendida pelos operários, por outro aparecia como uma forma de regular e até legitimar o descanso desta classe.

A Lei de Férias foi discutida em uma comissão que incluía os Secretários d CNT Lins Mario Poppe e João Lousada, e o deputado Afrânio Peixoto -sem mencionar o próprio proponente, Dodsworth- ( $O$ Paiz, 1 de julio de 1926, p. 7). O tema do trabalho não era algo novo para Peixoto, que também fizera parte da primeira composição do CNT, em 1923. Depois da aprovação, em fins de 1925, o ano de 1926 foi marcado por numerosas reuniões cujo objetivo era regular a medida. O relatório do anteprojeto ficou a cargo de Libanio da Rocha Vaz, representante patronal $\stackrel{3}{3}$, e a presidência do desembargador Ataulpho de Paiva.

No mês de julho, as reuniões entre CNT, parlamentares, patrões e empregados ocorreram praticamente todos os dias, e muitas vezes eram tensas. Segundo o periódico O Paiz, em certos encontros, que seguidamente se estendiam pela noite, "a intransigência de alguns oradores deixou transparecer alguma animosidade ( $O$ Paiz, 3 de julho de 1926, p. 5). Um dos artigos mais polêmicos foi o $8^{\circ}$, que previa: “Aos empregados e operários, dispensados nos últimos três meses do ano, serão pagos 15 dias de férias, uma vez que a retirada não tenha sido por falta grave”(O Paiz, 5 de julho de 1926, p. 7). Ao final da reunião em que o assunto foi discutido, por sugestão da Associação Comercial e da Associação dos Empregados no Comércio -ambas de Rio de Janeiro-, se chegou à seguinte formulação: “Aos empregados e operários com direito às férias (nos termos do artigo 4), que tenham sido dispensados, serão pagos os 15 dias de férias que ainda não tenham sido desfrutados, procedendo-se da mesma maneira nos casos de contrato de aluguel de serviço pelo período de u ano.”(O Paiz, 5 de julho de 1926, p. 7).

No início do mês de outubro de 1926, “depois de vários dias de árduos e constantes trabalhos”,(O Paiz, 3 de outubro de 1926, p. 25) a medida foi aprovada. As discussões, deste modo, ocorreram no interior do Estado e, como mencionado, sem ter sido diretamente impulsionadas pelo movimento operário organizado.

A tentativa de desmobilização dos trabalhadores com as leis trabalhistas ao longo dos anos 1920 parece ter sido assim percebida pelos anarquistas da época. Em uma edição de O Syndicalista (periódico da Federação Operária do Rio Grande do Sul, na época controlada pelos libertários) de março de 1927 se denunciava uma organização empresarial que burlava a Lei de Férias caracterizando a medida como lei filantrópica. La entidade defendia que era necessário conquistar direitos por meio da ação direta para depois garanti-los: “os operários mansos veem-se enganados nas suas esperanças. Muito bem assim! Pois querendo o ganso assado sem combate, isto não pode ser. Lutai para os vossos interesses e depois segurai-os!”( O Syndicalista, 27 de março de 1927, p. 8). 
Desta lei que não estava na ordem do dia e que parecia inofensiva vieram muitas dores de cabeça para o Estado. Já no informe do Ministro da Agricultura, Indústria e Comércio referente ao ano de 1926, a questão ganhou destaque:

Hoje sua ação [do CNT] é chamada para intervir na execução de importantes medidas legislativas, em que se amparam interesses de grandes classes patronais e operárias. Dentre essas medidas, merece destaque a que concede férias aos empregados do comércio, indústria e outras atividades, cujo regulamento lhe coube elaborar como órgão de sua fiscalização, e a nova lei das caixas de aposentadoria e pensões dos ferroviários, portuários e marítimos, que também regulamentou e a cuja execução vai presidir. (...) Sua função é hoje não somente consultiva, mas, também, fiscalizadora e executiva. $\underline{4}$

Na sequência do relatório, o Ministro informa que as reuniões do CNT, que deveriam ser quinzenais, passaram a ocorrer semanalmente devido ao aumento do número de processos relativos à caixa dos ferroviários e às férias ${ }^{5}$. No relatório do ano seguinte a situação não esfriou. Pelo contrário: segundo o Ministro Germiniano Lyra Castro, tais benefícios "vieram traçar à ação do Instituto limites muito mais amplos do que aqueles dentro dos quais vinha agindo até então ${ }^{6}$ ”. Castro relatou que ainda o número de reclamações referentes ao não cumprimento da Lei de Férias era muito grande e que a primeira polêmica dizia respeito à data de sua validação: afinal, os doze meses de trabalho contariam a partir do decreto (dezembro de 1925) ou da sua publicação no Diário Oficial (outubro de 1926)? No fim das contas, o que acabou valendo como marco foi o Decreto ${ }^{\underline{7}}$. Ao final desse relatório, Lyra Castro chama a atenção para um tópico marcante da cultura legal brasileira, e particularmente sensível no caso da lei de férias:

...não tendo o Congresso Nacional, paralelamente à aprovação da medida, autorizado as despesas e fornecido os recursos indispensáveis à sua eficiente fiscalização, ficou o Conselho Nacional do Trabalho praticamente impedido de velar pela integral execução da mesma lei, tanto quanto os favores por ela criados se estendem, na sua aplicação, a todo o território nacional. $\underline{8}$

Em Porto Alegre, por exemplo, em janeiro de 1929 estourou uma greve de trabalhadores e trabalhadoras da indústria têxtil exigindo o cumprimento da Lei de Férias. O argumento utilizado pelos patrões foi exatamente este: se concedessem férias a seus operários não teriam garantia alguma de que seus concorrentes do mercado também o fariam devido à completa falta de fiscalização. A. J. Renner, líder de os industriais e dono de uma das fábricas em greve, explicou a situação:

Nas condições presentes, torna-se impossível a observância da lei de férias, ressalvadas raríssimas exceções. O governo da República não nomeou, até agora, os funcionários que se deviam encarregar de sua execução e da necessária fiscalização. Nem sequer foi votada, ainda, a verba necessária para a instalação de uma delegacia ou repartição que, neste Estado, atendesse ao serviço da execução da lei de férias. Temos telegramas (...) de São Paulo, pelos quais estamos informados de que lá não está sendo cumprida aquela lei. O mesmo acontece no Rio de Janeiro (Diário de Notícias, 12 de janeiro de 1929, p. 9). $\underline{9}$

O patronato nacional, de maneira geral, foi bastante incisivo em relação à Lei de Férias. Em São Paulo era bastante forte a argumentação de tom moralista para rechaçar a lei. Se defendeu que os operários ficariam “ociosos, entregues aos vícios” (Munakata, 1981, p. 39). Somente os beneficiários originais da lei, os trabalhadores do comércio, seriam, desde o seu ponto de vista, merecedores das férias. Os empresários afirmavam "que o trabalho manual não é de modo algum fastidioso porque é puramente mecânico e repetitivo. As férias -afirmavam- se justificam para os trabalhadores do comércio e das oficinas, cujo serviço, de natureza intelectual, leva a mente ao esgotamento”(Munakata, 1981, pp. 39-40). 
Não foi por acaso que, ao se dirigir ao CNT em 1927, o Centro dos Industriais de Fiação e Tecelagem de São Paulo inicia sua carta com uma citação de Henry Ford: "Não podereis fazer maior mal a um homem do que permitir que folgue nas horas de trabalho” (Carone, 1977, p. 432).

Em 1931, depois de muitas polêmicas, desentendimentos e algumas greves, a medida foi revogada até nova normatização, e durante este processo novas dúvidas surgiram: o benefício havia sido automaticamente extinto? Até quando os patrões poderiam quitar as férias? O Decreto número 19.808, de 28 de Março de 1931, previa que o período de descanso deveria ser saldado até abril de 1932 e, para desgosto dos industriais, seria retroativo ao ano de 1930. Tal situação evidencia o jogo político do novo governo, agora a cargo de Getúlio Vargas: até então todas as medidas referentes à Lei de Férias se mostravam muito impopulares entre os industriais brasileiros; no entanto, eram igualmente notórias as dificuldades para sua implementação.

A questão relativa aos industriais era tão delicada que resolveu se separar a legislação a partir dos anos 1930: os trabalhadores do comércio e escritório teriam a sua própria norma (Decreto $\mathrm{n}^{0}$ 23.103). A lei possuía algumas diferenças em relação às férias do operariado, como a impossibilidade de parcelamento das férias em mais de dois períodos, o que era permitido aos trabalhadores fabris caso o patrão assim desejasse.

A nova regulamentação da lei para a indústria veio com o Decreto no 23.768, de 1934, o qual mantinha um texto muito parecido com o de 1926, à exceção do artigo $4^{\circ}$ : "O direito às férias é adquirido depois de doze meses de trabalho no mesmo estabelecimento ou empresa (...), e exclusivamente assegurado aos empregados que forem associados aos sindicatos de classe reconhecidos pelo Ministério do Trabalho, Indústria e Comércio. (Munakata, 1981, p. 82).

É clara aqui a tentativa do Estado de "amansar" o proletariado apropriando-se de leis anteriores. Ou seja, apesar de não muito usufruídas pela classe até então, essa e outras leis já existiam de maneira menos restritiva, porém, depois de 1930, o aparato estatal passou a vinculá-las aos sindicatos sob a sua égide. A tentativa de regulamentação e organização dos órgãos sindicais por parte do Estado pode ser considerada uma das grandes novidades do projeto varguista. Embora inicialmente fossem permitidos tanto o sindicalismo oficial -ou seja, reconhecidos pelo Ministério do Trabalho, Indústria e Comércio- quanto o livre, apenas quem fosse filiado às entidades do primeiro grupo poderia usufruir de uma série de benefícios previstos em lei, evidenciando que a ideia era encontrar nesse tipo de associação um "órgão consultivo e de colaboração do poder público”. (Barreto, 1996, p. 27).

Esse era o plano do governo brasileiro, mas não necessariamente a classe trabalhadora aceitou prontamente o papel que lhe caberia. Um caso a ser mencionado é o da Federação do Trabalho do Distrito Federal (FTDF). Em janeiro de 1933, enquanto se discutia a viabilidade de uma nova Lei de Férias, o jornal $O$ Radical trazia um artigo assinado por Jocelyn Santos, membro da FTDF e do Sindicato dos Trabalhadores do Livro e do Jornal -além de regular colaborador do veículo-. O texto em questão, intitulado “Férias! Férias!”, não poderia ser mais direto e constitui uma grande fonte para perceber como parte do operariado organizado via a questão naquele momento:

Constitui sempre uma questão irritante a obstinação de certos interessados em negar ao proletariado esse direito já conquistado em outras épocas. Em vão, o sentir unânime do trabalhador brada, aos ouvidos moucos dos adversários deste intuito social, que não há argumentos (gráficos ou não), capazes de o arredar do princípio assentado na massa obreira, de que esse direito arrancado no tempo do reacionarismo não pode ser violado numa época dita de liberalismo revolucionário. Não importa ao proletariado que a lei seja falha ou retorcida. Reforme-se a parte má e cumpra-se a parte aceitável. Tudo é possível fazer, uma vez que se tenha uma dose de boa vontade, por mínima que seja. Mas, nada disso tem acontecido. O intuito protelatório das discussões salta aos olhos de toda gente. Nada se quer fazer de proveitoso, senão para o bolso dos patrões. Portanto, só cabe ao proletariado serrar 
fileiras em torno do Governo Provisório e do Ministro do Trabalho, partidários intransigentes da Lei de Férias, conforme reiteradas declarações públicas, com o fim de ajudá-los no cumprimento da Lei.

Ainda há pouco, o sr. Salgado Filho afirmava perante uma assembleia numerosa de proletários cariocas que tiveram de resistir às impertinentes solicitações referentes ao protelamento da execução da lei aos beneficiados de 1930. Bem se verá como serão muito maiores as dificuldades daquele titular quando tiver de fazer executar a lei integralmente para os outros períodos anuais. $\mathrm{O}$ proletariado assiste o dever de gritar a plenos pulmões quando lhe oferecem alguma panaceia em troca do descanso anual: -Queremos férias! Queremos férias! (O Radical, 22 de janeiro de 1933, $\mathrm{s} / \mathrm{p})$.

É importante observar que tanto a FTDF quanto o jornal eram simpáticos ao governo Vargas. É verdade que apenas os industriais eram vistos como obstáculos ao cumprimento da lei e à formulação de uma nova Lei de Férias, porém, é igualmente notória a sua recusa a desempenhar apenas o papel de "para-choque" nos conflitos capital-trabalho. Poucos dias depois, o mesmo jornal relatou uma visita feita ao DNT onde foi constatado que havia mais de 12 mil processos referentes a férias em aberto -não é explicitado, porém, se a cifra refere-se apenas ao Rio de Janeiro ou a todo o país-.

Algumas semanas depois veio a "recompensa": a FTDF foi convidada pelo MTIC para eleger um representante que comporia a comissão responsável por elaborar uma nova Lei de Férias. Por unanimidade, foi escolhido o autor do texto sobre as férias, Jocelyn Santos, vice-presidente da União dos Trabalhadores do Livro e do Jornal. (O Radical, 13 de fevereiro de 1933, p. 5).

Em abril, enfim reunia-se a comissão, mas os relatos que $O$ Radical trazia não eram os mais animadores. Manchetes e palavras de ordem do tipo “A lei de férias virá dessa vez?” e “apesar das constantes reclamações do proletariado, ainda não foi possível concluir-se a redação do anteprojeto que regulará a lei de férias” podem ser encontradas diversas vezes nas páginas do periódico. Um dos grandes motivos pela demora não chega a ser exatamente uma surpresa: o "choque de opiniões” entre patrões e empregados na subcomissão que elaborava a Lei de Férias para a indústria. A questão envolvendo burguesia industrial e operariado fabril era tão polêmica que ocorreu uma separação entre o regulamento das férias para operários da indústria e aquele para comerciários, sendo que esse último ficou pronto bem antes, em abril de 1933, entrando em vigor quase cinco meses antes de seu correlato referente à indústria.

Segundo Tavares Barreto, presidente da comissão que elaborou o anteprojeto, havia a oposição acirrada dos patrões, que se constituía em um "obstáculo de grande monta”. Assim como havia feito nos anos 1920, o empresariado oferecera uma outra proposta no lugar das férias: a criação de seguros sociais. No entanto, conforme Antônio Bandeira de Mello, diretor-geral da Seção e membro da Comissão de Revisão do anteprojeto,

...os operários rejeitaram tacitamente a proposta dos patrões, e salientaram que muitos dos direitos propostos pela iniciativa do "seguro social” já estavam em vigor em inúmeras fábricas. Ao final dos trabalhos, apesar dos atrasos proporcionados pela oposição patronal, a iniciativa de criação de uma lei específica para garantia do direito de férias venceu por quantidade de votos na comissão. (Souza, 2007, p. 45).

Para O Radical, Jocelyn Santos explicou que "Os trabalhadores não abririam mão de Lei de Férias, por qualquer outra. É certo que pleiteariam oportunamente o Seguro Social, mas como complemento de novas leis sociais. Com a Lei de Férias não poderiam transigir, visto que era um direito já adquirido pelo proletariado." (O Radical, 20 de abril de 1933, p. 5).

A postura conciliatória e de defesa do Governo não impediu que a FTDF entrasse em conflito com o MTIC. 
Através de Santos, a Federação propôs que as férias fossem extensivas a todos os trabalhadores, inclusive assalariados rurais, chauffeurs e cocheiros de veículos particulares, diaristas ferroviários, tranviários e "tarefeiros de qualquer natureza". A entidade solicitou também a instalação imediata de colônias de férias no interior e no litoral do país assim como ocorria em outros lugares do mundo (O Radical, 27 de abril de 1933, p. 5). A pedida, porém, não foi atendida.

Apesar de garantida a permanência das férias, uma série de medidas protelatórias dos representantes dos industriais fazia com que a comissão andasse em marcha lenta (boicote a reuniões, alteração dos locais de encontro sem aviso prévio, longos discursos para "enrolar" e cansar os presentes...). Assim, enquanto as férias do comércio estavam prestes a entrar em vigor, em julho de 1933, a Comissão ainda aprovava os três primeiros artigos referentes às férias na indústria -e que sequer eram os artigos mais polêmicos, pois se referiam a quem tinha direito ao benefício (artigo $1^{\circ}$ ), o que era estabelecimento industrial $\left(\right.$ artigo $2^{\circ}$ ) e se industriais de estabelecimentos não-industriais estavam protegidos pela lei (artigo $3^{\circ}$ )-.

Apesar do justificado -e externado- pessimismo dos trabalhadores, no dia 7 de agosto de 1933 a Comissão encerrava seus trabalhos. E o anteprojeto enviado para apreciação de Salgado Filho, Ministro do Trabalho, contava com evidentes conquistas trabalhistas: a fiscalização da execução da lei seria feita pelas entidades trabalhistas, colônias de férias seriam estabelecidas e haveria redução no valor de passagens nas empresas de transporte da União a quem se destinasse a repouso por força do gozo em locais apropriados para férias. Muitas dessas questões, como vimos anteriormente, acabaram não fazendo parte do texto normativo final, como foi o caso das colônias de férias.

A nova Lei de Férias finalmente entrou em vigor em janeiro de 1934. Em 1937 o beneficio foi estendido aos tripulantes das embarcações nacionais, e em 1943 foi consagrado na Consolidação das Leis Trabalhistas (CLT).

A relação entre férias, Brasil e OIT é curiosa. Se por um lado o governo brasileiro buscava na entidade um espaço para fazer propaganda $\underline{10}$ e para conhecer novas formas de modernizar suas leis sociais, as discussões e temas que surgiam nas reuniões eram muito mais sugestivos do que propriamente normativos. Quando passou a legislar com frequência sobre as relações de trabalho, o Brasil de fato pensou em questões como acidentes de trabalho e o trabalho de mulheres e crianças que apareciam nas primeiras convenções. A jornada de trabalho, porém, levaria ainda muitos anos para ser regulamentada.

Ao mesmo tempo, o primeiro convênio da OIT relativo a férias apareceria apenas na sua $20^{\mathrm{a}}$ reunião, em Genebra, em 1936, talvez influenciada pelo governo da Frente Popular na França, mencionado anteriormente. O Convênio 54 previa um mínimo de 6 dias de descanso, e recomendava que esse número aumentasse progressivamente conforme o tempo de serviço (Organização Internacional do Trabalho, 1952, pp. 335-338). Nessa época, o Brasil já havia promulgado, revogado e reformulado sua Lei de Férias, mostrando um caminho normativo próprio e influenciado mais por suas questões e lutas internas do que pelas recomendações da OIT. Vejamos agora que lutas foram essas.

\section{A luta da classe trabalhadora por ócio e descanso}

A crescente demanda da classe trabalhadora brasileira por ócio, lazer e descanso encontrou forte respaldo na Lei de Férias, que pode não ter sido aprovada diretamente em função de suas lutas, mas certamente abrigou a seus interesses. O temor dos patrões de perder o controle sobre sua força de trabalho não era de todo irracional dentro de sua lógica: a entrega a toda sorte de vícios era tomada como uma certeza, mas é possível que, assim como o movimento operário organizado, eles também percebessem o tempo livre como um momento de interação de classe e de contatos com ideias comunistas e anarquistas, "vícios" ainda mais perigosos que jogos de azar e álcool. 
A burguesia industrial do Brasil tinha certa razão quando se dizia surpresa diante da aprovação de uma lei que nunca compôs a pauta de reivindicações do movimento operário, como exposto anteriormente. Nas resoluções do I Congresso Operário Brasileiro, em 1906, por exemplo, comandado por correntes anarquistas, dentre os 14 temas discutidos, aparecem a luta pelas oito horas diárias e contra o militarismo, e até questões que viriam a ser regulamentas alguns anos depois, como acidentes de trabalho e o trabalho feminino e de menores. Nada de férias. O Segundo Congresso Operário Brasileiro realizado em 1913, ainda sob coordenação de grupos anarquistas, trazia dez temas a mais que o congresso anterior; destacam-se os acréscimos de educação e higiene, mas as férias ainda estavam ausentes. (Pinheiro,Hall, 1979, pp. 172-229).

Os libertários reivindicavam que o operariado seguisse na luta e não se deixasse enganar por leis filantrópicas. Em Porto Alegre, O Syndicalista, periódico da FORGS, de orientação anarquista, em sua edição de outubro de 1925 relata o $3^{\circ}$ Congresso Operário Regional realizado um mês antes. Tal congresso tinha como grande bandeira a defesa das 44 horas semanais. Já estava em vigor a Lei de Acidentes de Trabalho e em funcionamento o CNT, mas a Federação não fazia menção nem à lei nem ao órgão.

Contudo, como já mencionado, se não havia uma demanda operária por férias remuneradas especificamente, o lazer e o ócio, surgiam sim como questões, e a efervescência de piqueniques, clubes recreativos, carnavalescos e esportivos dão um pouco a medida do fenômeno não só no Brasil, mas em muitos outros países. As atividades de lazer fora das fábricas cresciam em número, importância e diversidade.

Depois da promulgação da Lei de Férias o tema começou a reverberar com mais força, e o termo férias começou a aparecer com certa frequência nos discursos do operariado organizado. Sempre que convocou grandes comícios ao redor do Brasil, especialmente nas comemorações do $1^{\circ}$ de Maio, o PCB (e posteriormente o BOC) defendeu o cumprimento do benefício. Em Porto Alegre, no ano de 1927, por exemplo, em pronunciamento ao jornal Correio do Povo referente à data, o Partido mencionou o tema dentro de uma ampla reivindicação pelo cumprimento de todas as leis trabalhistas recém-aprovadas:

Queremos o dia de 8 horas. Reclamamos um aumento de ordenados, que esteja em relação com o aumento do custo de vida. Reivindicamos o cumprimento das leis de férias, acidentes de trabalho e de menores, votadas pela própria burguesia e sancionadas pelo governo dos fazendeiros de café. (Correio do Povo, 1 de maio de 1927, p. 4).

Passado um ano, em um boletim comemorativo em relação à mesma data no Diário de Notícias, o BOC também se lembrou do não cumprimento da lei, embora de maneira tímida:

...Assim, é necessário lutar pelo aumento geral dos salários, generalização do pagamento semanal, nenhum desconto nos salários, metade dos salários quando o trabalhador cair doente, extinção das multas, horário semanal de 44 horas, horário de 7 horas para as mulheres e de 6 horas para os menores, direito de atrasar-se 5 minutos e em geral lutar pela baixa dos aluguéis e barateamento dos gêneros de primeira necessidade. Cumprimento da Lei de Férias. (Diário de Notícias, 3 de maio 1928, p. 9).

Esses eventos públicos, além de propagandearem o PCB e o BOC, serviam também em grande medida para divulgar as novas leis ao operariado em geral. Uma das estratégias dos comunistas para ganhar influência entre a classe trabalhadora foi justamente defender a aplicação imediata de todas essas medidas, que precisariam, portanto, ser do conhecimento de seus beneficiários. Dentre elas, amplamente propagandeadas em comícios, Gomes afirma que a Lei de Férias era "um 'verdadeiro trunfo' para arregimentar gente" (Gomes, 2005, p. 160), indo ao encontro do que foi dito anteriormente: os trabalhadores não tinham inicialmente o direito a férias remuneradas em seu horizonte de expectativas, mas a lei aglutinou e legitimou os seus crescentes desejos por maior tempo livre. 
No mês de fevereiro de 1928, em São Paulo, durante um comício que marcou a fundação do BOC paulista, a primeira promessa da nova agremiação era de que pleitearia "a execução integral da Lei de Férias" e do Código de Trabalho. (In Pinheiro; Hall, 1979, p. 295). Um ano depois de propor a criação de um Comité pró Lei de Férias, e percebendo que a via legal parecia insuficiente à sua execução, os trabalhadores gráficos daquela cidade se declararem em greve. Liderada pelos comunistas, a parede teve início em março de 1929 e durou 72 dias, mas acabou violentamente reprimida. (Karepovs, 2006). Se rebelava exigindo exclusivamente o cumprimento desse benefício: "A lei de férias vai de encontro à ambição de certos patrões e por isso continuará sendo burlada - Em todo caso, a reunião de hoje, na rua Acre, colocará o governo entre a cruz e a caldeirinha” (A Esquerda, 18 de janeiro de 1928, p. 1). Quem escrevia era o deputado Azevedo Lima (BOC), que convocava diversos sindicatos para a reunião que aconteceria na sede da União dos Operários em Fábricas de Tecidos naquela noite.

A partir dos anos 1930, a luta pelo direito a 15 dias de férias remuneradas estava consolidada. Ao mesmo tempo em que muitas greves e protestos varriam o Brasil, o número de países que concedia este direito era cada vez maior. Durante os meses de novembro e dezembro de 1932 -quando uma nova norma para regularizar as férias voltava a ser discutida-, até mesmo os anarquistas, por meio do periódico libertário A Plebe, deram importância ao tema. Na primeira edição de sua "nova fase" -a primeira durou de junho de 1917 a fevereiro de 1927-, de 19 de novembro de 1932, o jornal trazia uma série de reclamações: da União dos Operários Metalúrgicos, que "se agitava[m] no sentido de não deixar burlar a Lei de Férias e a lei de 8 horas"; da União dos Trabalhadores da Light, que havia realizado uma assembleia "para tratar de sua reorganização e reclamar a Lei de Férias"; da Liga dos Operários da Construção Civil, que "reclama[va] o cumprimento da Lei de Férias"; da União dos Empregados em Cafés, que "se organiza[va] em torno das férias”. (A Plebe, 19 de novembro de 1932, p. 3). Na semana seguinte o jornal estampava uma nota oficial da Federação Operária de São Paulo (FOSP), também de orientação anarquista, que defendia a criação de um Comité Pró Férias e a retomada da ação direta (A Plebe, 26 de novembro de 1932, p. 4).

No dia 3 de dezembro, a publicação reproduz outra nota da FOSP, dessa vez sobre a greve pela Lei de Férias ocorrida nas Indústrias Reunidas Francisco Matarazzo. (A Plebe, 3 de dezembro de 1932, p. 4). Segundo a entidade, após 12 dias de paralisação, "apesar dos esforços do Ministério do Trabalho em fazer fracassar a greve pacífica”, a parede "alcançou estrondosa vitória”: "Segundo estamos informados, os operários das indústrias Matarazzo, conquistaram o seguinte: pagamento quinzenal, oito horas de trabalho, pagamento das férias e aumento de 20\%”. (A Plebe, 17 de dezembro de 1932:4). Os anarquistas, que já haviam identificado na Lei de Férias uma tentativa do Estado de acalmar os ânimos da classe trabalhadora, agora exigiam seu cumprimento -desde que sem a intermediação das esferas estatais-.

Ainda em São Paulo, o processo de oficialização da União dos Trabalhadores Gráficos (UTG) de São Paulo dá a medida da popularidade que essa lei adquiriu. A entidade era controlada por trotskistas, que até aquele momento também optavam por não integrar os sindicatos reconhecidos pelo MTIC. A partir da nova Lei de Férias e da necessidade de se estar em um sindicato oficial para dela usufruir ocorreu uma pressão da base pela oficialização da UTG:

Diante na nova lei de férias, determinando que só terão direito ao gozo de férias os operários que se encontram organizados em sindicatos oficializados, a nossa existência de sindicato livre está seriamente ameaçada. A Comissão Executiva, em diversas reuniões, examinou detidamente o assunto e verificou a impossibilidade de encontrar, por si só, uma solução que venha a resolver a situação bastante delicada em que estamos colocados. Por outro lado, observamos que a tendência manifestada por alguns companheiros, para a oficialização da UTG, se reforça cada vez mais. Podemos mesmo adiantar que hoje, quase a totalidade da corporação é pela oficialização do nosso sindicato, não só para a obtenção de férias, como também para salvar a própria unidade organizadora 
dos trabalhadores gráficos (A Platéia, 27 de fevereiro de 1934, p. 3).

A UTG optou por oficializar-se, e este caso evidencia a força e o apelo que esta lei teve entre a classe trabalhadora e os operários industriais em particular, como se disse.

Os patrões, por sua vez, também se organizaram e articularam conjuntamente ações para garantir seus interesses. Se o operariado lutava pelo cumprimento do direito a férias é porque havia uma classe disposta a não obedecê-lo.

No livro Senhores e Caçadores, E. P. Thompson nos apresenta uma grande discussão acerca dos domínios da lei e como, mais do que uma pura e simples estrutura de dominação, o direito funciona como um campo complexo de lutas. Segundo o historiador inglês, por mais que a lei seja em alguma medida um instrumento ideológico, suas regras e categorias "penetram todos os níveis da sociedade, efetuam definições horizontais e verticais dos direitos e os status dos homens” (2010, p. 288). Dessa forma, mesmo as classes dominantes estavam preocupadas e sujeitas (em maior o menor medida) à lei.

Isto ajuda a explicar porque a burguesia industrial do Brasil pensou nas mais diversas formas de burlar o cumprimento da Lei de Férias. Nos primeiros anos, a estratégia era simples: os trabalhadores eram despedidos depois de onze meses de trabalho, já que era preciso trabalhar um ano no mesmo local. Porém, suas formas de escapar ao cumprimento da lei foram mudando com o passar do tempo.

Uma reunião do Centro da Indústria Fabril do Rio Grande do Sul (CINFA) em 1931, por exemplo, apresenta a articulação nacional dos empresários e muitas das formas que eram pensadas para escapar de suas obrigações. Seu líder, o já mencionado empresário A. J. Renner relatou que, enquanto estava em viajem ao Rio de Janeiro, se encontrou com Jorge Street, importante industrial carioca. Neste encontro se discutiu o tema das férias:

[Street aconselhou] que os industriais deste Estado organizassem o registro dos seus operários deixando-o incompleto por falta das informações que competem serem dadas pelos operários, a fim de evitar que possam os fiscais multá-los, quando for estabelecida essa fiscalização, o Centro tinha dirigido circulares aos associados transmitindo-lhes esse conselho. Que esse trabalho deverá ser feito com muita discrição, a fim de evitar que se levante alarme sobre as férias. (CINFA, 13 de julho de 1931, pp. 77-78).

As carteiras profissionais, como dissemos, eram a forma de controle do operariado por parte dos patrões: continham idade, tempo de serviço, faltas, etc. Quem desejasse sair de férias deveria apresentá-la corretamente preenchida, e qualquer erro atrasaria ou até mesmo anularia a possibilidade do gozo do benefício. Ou seja, mais uma vez e através de uma fonte diferente percebemos que a Lei de Férias foi uma enorme dor de cabeça para a burguesia industrial de todo o Brasil, tanto é assim que existia uma recomendação padrão de como fraudar o seu cumprimento.

Para as operárias a situação era muito pior: alguns patrões afirmavam que "a fotografia [da carteira] no pode[ria] ser tirada com brincos e colares” (Santos, 2015, p. 48). Assim, até que a trabalhadora providenciasse uma nova foto, o patrão ganharia um tempo a mais.

O texto da nova Lei de Férias de 1934 expõe uma série de questões reclamadas pelos trabalhadores desde muito tempo. O artigo 30 do Decreto 23.768 assegurava, por exemplo, a impossibilidade de despedir os empregados que pedissem o cumprimento da lei, indicando que esta era uma prática recorrente. Portanto, a experiência com a medida até então apresentava uma classe operária que se organizava para exigir o cumprimento de a lei e que muitas vezes pagava um alto preço diante de um patronato unido e determinado a desobedecê-la. 


\section{Considerações finais}

O historiador inglês Edward Thompson defende que é necessário considerar as múltiplas experiências para a constituição de uma classe. Ao sublinhar o papel da "experiência humana" reivindicou que homens e mulheres retornassem como sujeitos à explicação, embora

...não como sujeitos autônomos, "indivíduos livres", mas como pessoas que experimentam suas situações e relações produtivas determinadas como necessidades e interesses e como antagonismos, e em seguida "tratam" essa experiência em sua consciência e sua cultura [...] das mais complexas maneiras (sim, “relativamente autônomas”) e em seguida (muitas vezes, mas nem sempre, através das estruturas de classe resultantes) agem, por sua vez, sobre sua situação determinada (Thompson, 1981, p. 182).

As experiências que formam essas culturas e consciências não se dão somente no local de trabalho. Rodolfo Porrini nos lembra de que este e outros autores britânicos como Hobsbawm e Richard Hoggart

...practicaron un enfoque más rico para conocer las clases trabajadoras, ampliando la restringida noción de "movimiento obrero", y aunque su centro de interés no era obviamente el "tiempo libre", sin duda lo incluían al considerar varios de sus aspectos. Es decir, en estos estudios se reconocía de hecho el interés de estudiar y analizar el “tiempo libre” de los trabajadores. (Porrini, 2011, p. 106).

Assim, se por muito tempo se pensou que as férias no se constituíram como una das grandes e clássicas bandeiras de luta do operariado organizado brasileiro durante o século XX, é necessário levar em conta uma série de fatores para entender porque se lutou tanto por algo que, à primeira vista sequer estava no seu horizonte.

Em um primeiro momento, é importante recordar que o que hoje se compreende por férias não é exatamente o mesmo que se entendia na época. Parece que havia um sentido mais amplo, que englobava as noções de tempo livre, ócio e relações de amizade e sociabilidade fora das fábricas. Além disso, havia uma crescente demanda por direitos -tanto no Brasil como em outros países- e a criação da OIT é uma resposta a isto. Sendo assim, é muito possível que outras pesquisas acerca de leis trabalhistas ainda pouco exploradas encontrem resultados semelhantes em termos de luta e mobilização do operariado, que começava a vislumbrar no direito mais uma possibilidade de garantir melhores condições de vida e de trabalho.

Além disso, como se defendeu, a ausência da palavra não indica uma correspondente ausência de vontade ou desejo. Quando se percebe a proliferação de atividades desde as décadas finais do século XIX e especialmente nas primeiras décadas do século seguinte se buscou outras explicações para a atração que os operários tiveram pelas férias. As leis ao redor do mundo, na verdade, em grande medida legitimaram uma demanda que já estava presente nas vidas da classe trabalhadora, que agora tinha algo mais concreto pelo que lutar.

Essas questões internas brasileiras somadas à aparente má vontade do Estado em atender as principais bandeiras trabalhistas ajudam a explicar um pouco melhor a relação do país com a OIT -estudos que foquem outros países podem ajudar a medir o real peso da entidade nos processos normativos de diferentes partes do mundo-. Se por um lado o Brasil se preocupava em aparecer como uma nação moderna diante dos olhos dos membros da OIT, também não era tão certo assim que seguiria suas recomendações ou que assinaria seus convênios, e no caso das férias, antecipou à entidade.

O que se tentou fazer neste trabalho foi justamente compreender as luchas por descanso remunerado, especialmente por férias, da classe trabalhadora, principalmente a brasileira, na tentativa de relacionar até que ponto o país estava aliado com a OIT e com outros países-membros no período. Se é importante considerar as atividades de ócio na formação de uma cultura operária, assim como no desenvolvimento de 
sociabilidades e consciência política, nosso foco principal foi mostrar as formas de luta para garantir um tempo livre no qual se pudessem realizar estas e outras atividades, e como as mais variadas leis de férias foram surgindo a partir destas realidades.

\section{Arquivos consultados}

Arquivo Histórico de Porto Alegre Moysés Vellinho (AHPAMV)

Arquivo Histórico do Rio Grande do Sul (AHRS)

Fundação Biblioteca Nacional (FBN)

Museu da Comunicação Social Hipólito José da Costa (MCSHJC)

Núcleo de Pesquisa em História UFRGS (NPH/UFRGS)

Biblioteca do Tribunal Regional do Trabalho da $4^{\circ}$ Região (BTRT)

Centro de Documentação e Memória da UNESP (CEDEM/UNESP)

Arquivos Brasileiros da Universidade de Chicago (http://brazil.crl.edu/):

Câmara dos Deputados (http://www2.camara.leg.br)

Hemeroteca Digital Brasileira da Biblioteca Nacional (HDB/BN)

\section{Notas}

1 O país inclusive foi chamado de "primeira experiência de Estado de bem-estar". (Cf. Finch apud Porrini, 2002, p. 100).

2 Há poucas referências às férias antes de 1925 -tanto por parte do Estado como por parte dos trabalhadores-. No entanto, encontramos alguns casos: houve um Decreto em 1916 que conferia 15 dias de descanso remunerado ao funcionalismo público em Santa Catarina. A historiadora Rafaela Leuchtenberger defende que este beneficio foi devido à ação da associação mutualista do sector. Arthur Vitorino, por sua vez, expõe que em 1907 o diretor d Instituto de Assistência à Infância do Rio de Janeiro sugeriu que os operários gráficos menores de 18 anos tivessem direito a 15 dias de férias remuneradas; Robério Souza identifica uma greve de ferroviários na Bahia no ano de 1909, na qual um dos 18 pontos de reivindicação era o direito a 15 dias de férias; João Marcelo Pereira dos Santos, ao tratar dos trabalhadores da companhia Light de São Paulo, expõe que uma das exigências da Liga dos Trabalhadores da Light, fundada em 1919, era o "direito a férias anuais”. (Cf. Leuchtenberger, 2012, p. 80). VITORINO, Artur José Renda. Processo de trabalho, sindicalismo e mudança técnica: o caso dos trabalhadores gráficos em São Paulo e no Rio de Janeiro, 18581912. Dissertação (Mestrado em História), Campinas: Unicamp, 1995, p. 94; SOUZA, Robério S. Tudo Pelo Trabalho livre! Trabalhadores e conflitos no pós-abolição (Bahia, 1892 - 1909). Salvador: EDUFBA/FAPESP, 2011, p. 117; SANTOS, João Pereira Marcelo dos. Energia Elétrica e Poder Político. Trabalhadores da Light São Paulo - 1900-1935. São Paulo: expressão Popular, 2015, p. 160.

$\underline{3}$ A representação patronal de Osório de Almeida apresenta uma situação curiosa. No momento da convocação dos membros do Conselho, em 1923, este integrante disse que a classe patronal estava subrepresentada, porque somente um de seus assentos estivera ocupado. Em clara tentativa de assegurar uma maior representação para a burguesia brasileira, Osório reclamou que havia sido convocado para o Conselho 
"por suas funções de Inspetor Geral das Estradas de Ferro”, e não por ser Vice-Presidente do Centro Industrial Brasileiro. A reclamação não foi aceita, e se definiu que Osório era, de fato, um representante patronal. Cf. Ata da Primeira Sessão do CNT. Revista do Conselho Nacional do Trabalho, Rio de Janeiro, ano I, n. 1, julho de 1925, p. 50. FBN.

4 BRASIL. Relatório apresentado ao Presidente da República dos Estados Unidos do Brasil pelo Ministro de Estado da Agricultura, Indústria e Comercio - Germiniano Lyra Castro - 1926, p. 353. Arquivos Brasileiros, Universidade de Chicago. Disponível em: < http://brazil.crl.edu/bsd/bsd/u2022/> Acesso em: 06 mar 2015.

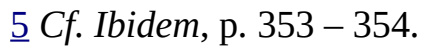

6 BRASIL. Relatório apresentado ao Presidente da República dos Estados Unidos do Brasil pelo Ministro de Estado da Agricultura, Indústria e Comercio - Germiniano Lyra Castro - 1927, p. 289. Arquivos

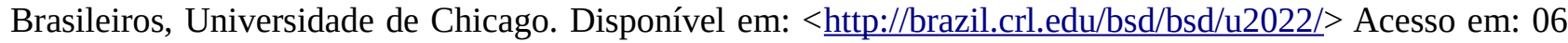
mar 2015.

Z Ibidem, p. 290

8 Ibidem, p. 291.

9 Sobre esta greve, ver Nunes, 2014.

10 Em 1925, por exemplo, o delegado belga M. Mertens questionou o "paraíso na terra” que o governo Arthur Bernardes tentava vender no exterior, citando as perseguições a operários brasileiros, a violação dos sindicatos e as deportações para o Oiapoque. O delegado terminou sua manifestação de maneira categórica: “que Deus me preserve de ser obrigado a viver em semelhante país”. (Cf. Carone, 1989, p. 232).

\section{Bibliografía}

Araújo, A. M. C. (1994). Construindo o Consentimento: corporativismo e trabalhadores no Brasil dos anos 30 (Tese de doutorado), Unicamp, Campinas, Brasil.

Barreto, A. A. B. (1996). O movimento operário rio-grandense e a_intervenção estatal: a FORGS e os Círculos Operários (1932-1935). (Tese de doutorado), UFRGS, Porto Alegre, Brasil.

Carone, E. (1993). A II Internacional pelos seus congressos (1889-1914). São Paulo: Edusp, Anita.

Carone, E. (1989). Classes Sociais e Movimento Operário. São Paulo: Ática.

Carone, E. ( 1977). O pensamento industrial no Brasil (1880 - 1945). São Paulo: DIFEL.

Carone, E. (1974).A Primeira República. São Paulo: DIFEL.

Fortes, A. (2007). Férias pra quê? Revista de História, v. 17, p.30-34 Recuperado de: http://www.revistadehistoria.com.br/secao/capa/ferias-para-que.

Fortes, A. (2004). Nós do Quarto Distrito: a classe trabalhadora porto-alegrense na Era Vargas. Rio de Janeiro: Garamond.

Gomes, A. C. (2005), A Invenção do trabalhismo (3ºd.). Rio de Janeiro: Editora FGV.

Gomes, A. C. (1979). Burguesia e trabalho: Política e legislação social no Brasil 1917-1937. Rio de Janeiro: Campus. 
Hardman, F. F. (1981). Nem pátria nem patrão: vida operária e cultura anarquista no Brasil. São Paulo: Brasiliense.

Hobsbawm, E. (2000). A formação da cultura da classe operária britânica. En E. Hobsbawm, Mundos do Trabalho: novos estudos sobre História Operária. São Paulo: Paz e Terra.

Horden, F. (1990), Genèse et vote de la loi du 20 juin 1936 sur les congés payés. Le Mouvement social, 150, 19-30. Recuperado de: http://www.jstor.org/stable/3778649.

Karepovs, D.(2006). A classe operária vai ao parlamento: o Bloco Operário e Camponês do Brasil (1924 1930). São Paulo: Alameda.

Leuchtenberger, R. (2012). A organização e a atividade das associações de socorro mútuo de Florianópolis SC (1886-1930). Revista Mundos do Trabalho, 4(7), 57-84. Recuperado de https://periodicos.ufsc.br/index.php/mundosdotrabalho/article/view/1984-9222.2012v4n7p57/23294.

Lima, M. A. H. (2005) Legislação e Trabalho em Controvérsias Historiográficas: o projeto político dos industriais brasileiros (Tese de doutorado), Unicamp, Campinas, Brasil.

Martins, C. G. (2000). Revista do Trabalho: uma contribuição para o Direito do Trabalho no Brasil (Tese de mestrado), UFF, Niterói, Brasil.

Munakata, K. (1981). A legislação trabalhista no Brasil. São Paulo: Brasiliense.

Nunes, G. M. (2014). O operariado fabril e a Lei de Férias: a greve de janeiro de 1929 em Porto Alegre. Revista Escritas, 6, 127-152.

Organización Internacinoal Del Trabajo (1952). Convenios y recomendaciones: 1919-1951. Genebra: Albert Kunding.

Pastoriza, E. (2008). El turismo social en la Argentina durante el primer peronismo. Mar del Plata, la conquista de las vacaciones y los nuevos rituales obreros, 1943-1955. Nuevo Mundo. Recuperado de https://nuevomundo.revues.org/36472.

Pinheiro P. S. y Hall, M. M. (1979). A Classe Operária no Brasil 1889 - 1930 - documentos. São Paulo: Alfa Ômega.

Porrini R. (2011). Izquierda uruguaya y culturas obreras. Propuestas al “aire libre”: pic-nics y paseos campestres en Montevideo, 1920-1950”.Revista Mundos do Trabalho,3(6), 105-129.

Porrini, R. (2002). La construcción de una fuerza social: el nacimiento de la nueva clase trabajadora uruguaya en el decenio de 1940. (Tesis de maestría), UDELAR, Montevideo, Uruguay.

Richez, J. y Strauss, L. (1990). Généalogie des vacances ouvrières. Le Mouvement social,150, 3-18. Recuperado de http://www.jstor.org/stable/3778648.

Sirot, S. (1996) Les congés payés en France avant le Front Populaire: l'exemple des ouvriers parisiens de 1919 à 1935.Vingtième Siècle, 50, 89-100.

Santos, J. P. M. (2015). Energia Elétrica e Poder Político. Trabalhadores da Light São Paulo - 1900-1935. São Paulo: expressão Popular.

Souza, S. F. (2007). Coagidos ou Subornados: trabalhadores, sindicatos, Estado e as leis do trabalho nos anos 1930. (Tese de doutorado), Unicamp, Campinas, Brasil. 
Thompson, E. P. (2010). Los orígenes de la Ley Negra. Un episodio de la historia criminal inglesa. Buenos Aires: Siglo Veintiuno Editores.

Thompson, E. P. (1981). A Miséria da Teoria ou um Planetário de erros. Rio de Janeiro: Zahar. 